\title{
Risk of First-Episode Schizophrenia in Aged Adults Increased During COVID-19 Outbreak
}

\author{
Wei Hu${ }^{1} \cdot \mathrm{Li} \mathrm{Su}^{2,3} \cdot$ Deyong $\mathrm{Li}^{1} \cdot \mathrm{Yi}_{\mathrm{Zhou}} \mathrm{Zho}^{4,5} \cdot$ Jing $\mathrm{Zhu}^{1}$
}

Accepted: 1 October 2021

(C) The Author(s), under exclusive licence to Springer Science+Business Media, LLC, part of Springer Nature 2021

\begin{abstract}
We noticed an unusual increase of aged adults in first-episode schizophrenia in January and February 2020 since the outbreak of COVID-19. This retrospective study aims to statistically validate this observation and find potential risk factors, if applicable. The demographics of schizophrenia in outpatients (both first-episode and follow-up) from January to March 2020 (36,624 records) and similar periods of 2017-2019 (114,141 records) were analyzed and compared to minimize seasonal influence. Limited personal information (age, gender, approximate residence) was investigated to find risk factors. After considering seasonal factors such as the Spring festival, the age of the first-episode schizophrenia was significantly increased in January $(46.60 \pm 15.14)$ and February $(51.53 \pm 14.74)$ but went back to normal in March 2020 (38.89 \pm 14.59$)$, compared with similar periods from

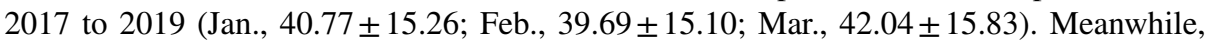
a slight but not significant change was found in the distribution of gender and approximate residence (urban/suburb). Our data supported that risk of first-episode schizophrenia in aged adults increased during the COVID-19 outbreak, which is consistent with the fact that COVID-19 is more lethal to elders. Public healthcare should prepare in advance for potential risks in public mental health, especially for elders.
\end{abstract}

Keywords Schizophrenia $\cdot$ COVID-19 $\cdot$ Mental disorders $\cdot$ Age $\cdot$ Public health $\cdot$ Risk factor

COVID-19 pandemic has hit the world for more than 18 months. In addition to the direct medical, social, and economic burdens, COVID-19 outbreak also had a significant impact on the mental health of various populations. As we learn more about it, recent studies have suggested that this pandemic could affect mental health both

Jing Zhu

drzhujing@163.com

1 The Affiliated Xuzhou Eastern Hospital of Xuzhou Medical University, Xuzhou, Jiangsu, China

2 CAS Key Laboratory of Behavior Science, Institute of Psychology, Chinese Academy of Sciences, Beijing, China

3 Department of Psychology, University of Chinese Academy of Sciences, Beijing, China

4 Department of Neurobiology, Army Medical University, Chongqing, China

5 Chongqing Key Laboratory of Neuroscience, Chongqing, China 
directly and indirectly. Direct influence can be seen in patients with abnormal sensation such as loss of smell or taste, which suggested a neurological mechanism underlying virus infection (Parma et al., 2020). Indirect influence to mental health is mainly caused by social stress and anxiety during pandemic, similar to previous reports during other disease outbreak (Chen et al., 2006) such as SARS, MERS, and swine flu (Taha et al., 2014). However, in contrast to previous reports, recent studies suggest that mental status is more widely and comprehensively affected in populations that were not infected. According to a Hong Kong study, mental health in healthy populations deteriorated during the COVID-19 pandemic, with increased anxiety and depressive symptoms (Choi et al., 2020). Another study found that the COVID-19 pandemic generated many transient psychotic episodes linked to emotional stress (Valdes-Florido et al., 2021).

As a severe psychotic disorder, risk of first-episode schizophrenia can be associated with genetic, cortical dysregulation but not significant public health events (McCutcheon et al., 2020). However, a significant number of recent studies have suggested a close relationship between COVID-19 outbreak and schizophrenia. During the COVID-19 outbreak, two patients with no history of psychiatric disease acquired COVID-19-related delusional themes and unusual behaviors, according to a case report (Oloniniyi et al., 2021). Another case report revealed that a 19-year-old Chinese-American student developed schizophrenia for the first time during a lockdown, implying that social isolation has a particular impact on individuals (Belvederi Murri et al., 2021). Mental diseases increased by $6.8 \%$ during COVID-19 lockdown, according to a cross-sectional study by Karuppiah et al., with schizophrenia and acute transitory psychosis being particularly prominent (Jagadheesan et al., 2021). However, the impact of social stress on the onset of schizophrenia is still unrecognized when the COVID-19 epidemic has just broken out.

Here in the Affiliated Xuzhou Eastern Hospital of Xuzhou Medical University, a first-class psychiatric hospital with more than 100,000 outpatients per year, an unusual increase of aged adults diagnosed with first-episode schizophrenia was noticed by psychiatrists from several departments since January 2020, when COVID-19 outbroke in China. Although schizophrenia can occur in people of any age, previous studies showed that the age of onset tends to be in the late teens to the early $20 \mathrm{~s}$ for males, and the late $20 \mathrm{~s}$ to early $30 \mathrm{~s}$ for females (Charlson et al., 2018; Loranger, 1984; Neill et al., 2020). It is uncommon for schizophrenia to be diagnosed in a person younger than 12 or older than 40 (Bailly, 2009; Suen et al., 2019). However, special events such as war (He et al., 2019), epidemics (McGrath et al., 1994), and major holidays (Aviv et al., 2011) could induce the onset of schizophrenia in a specific population and thus change the age of onset, according to previous reports. In this retrospective study, we thoroughly investigated clinical records from January 2020 to March 2020 to validate this observation. The age of first diagnosis (AFD) was collected. Because the Spring festival of 2020 was also in January, and big holidays like Spring festival could have significant impacts on the mental states of people (Beauchamp et al., 2014). Major seasonal factors such as the Spring festival was considered but cannot explain the unexpected rising of AFD alone. Limited personal information such as gender, and approximate address (urban/suburb) was accessed to find out potential risk factors. 


\section{Methods}

\section{Study Overview and Participants}

As a retrospective study, all records are collected from patients who visited the Affiliated Xuzhou Eastern Hospital of Xuzhou Medical University, a first-class psychiatric hospital at Grade 3 with more than 100,000 outpatients per year. For each case used in this study, a clinical diagnosis must be made by qualified psychiatrists following the International Classification of Diseases 10th Edition (ICD-10). Clinical records from January 1 to March 31 were chosen to represent the progressive influence of the COVID-19 outbreak. We divided the clinical cases into first-episode and follow-up patients (patients with stable conditions after outpatient or hospitalization treatment). Diagnostic results and limited personal information (gender, age, and approximate address) are collected and analyzed to find potential risk factors.

\section{Data Alignment}

Because big holidays such as Christmas (Sansone \& Sansone, 2011) or Spring festival might have significant impacts on mental states of people, clinical records in similar periods near Spring festival from 2017 to 2019 were collected and analyzed as reference to minimize seasonal influence. Since Spring festival is a holiday in the lunar calendar, the date corresponding to the Gregorian calendar varies from year to year. The statistics were aligned to the exact date of Spring festival instead of a specific date in each year (Table 1). The Spring festival was January 28, 2017, February 18, 2018, February 5, 2019, and January 25, 2020.

\section{Data About COVID-19}

For the countrywide situation of COVID-19, statistical data were collected from the website of the National Health Commission of the PRC (http://en.nhc.gov.cn, English version available), includes the number of new confirmed cases, new severe cases, new deaths, new suspected cases, new cured cases, cases released from medical observation on the same day, existing confirmed cases, existing severe cases, cumulative discharges, cumulative deaths, cumulative confirmed cases, existing suspected cases, cumulative close contacts traced, and cases under medical observation.

Table 1 Date alignment to reduce seasonal influence

\begin{tabular}{lllll}
\hline & 2017 & 2018 & 2019 & 2020 \\
\hline "January" & $1.4-2.3$ & $1.23-2.22$ & $1.12-2.11$ & $1.1-1.31$ \\
"February" & $2.4-3.4$ & $2.23-3.23$ & $2.12-3.12$ & $2.1-2.29$ \\
"March" & $3.5-4.4$ & $3.24-4.23$ & $3.13-4.12$ & $3.1-3.31$ \\
Spring festival & 1.28 & 2.18 & 2.5 & 1.25 \\
\hline
\end{tabular}



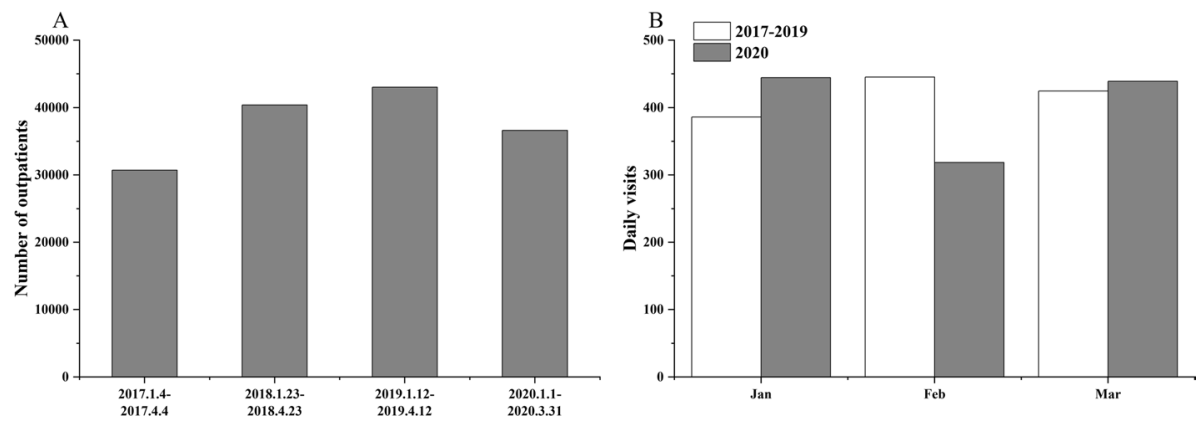

Fig. 1 Overview of outpatients. A Outpatient volume from January to March 2020 and similar periods from 2017-2019. B Daily visits from January to March 2020 and similar periods from 2017-2019. Data in 2017, 2018, and 2019 were averaged. Similar periods: "January" (1.4-2.3 in 2017, 1.23-2.22 in 2018, 1.12-2.11 in 2019, 1.1-1.31 in 2020, 31 days in total), "February" (2.4-3.4 in 2017, 2.23-3.23 in 2018, 2.12-3.12 in 2019, 2.1-2.29 in 2020, 29 days in total), and "March" (3.5-4.4 in 2017, 3.24-4.23 in 2018, 3.13-4.12 in $2019,3.1-3.31$ in 2020, 31 days in total)

\section{Statistics}

SPSS 22 (IBM, USA) was used for statistical analysis. To determine the incidence of schizophrenia, we calculated the ratio of patients who had it. To further understand the trends, the mean AFD of the first-episode patient and the mean age of the follow-up patients were calculated. Independent sample $t$ test was used for the analysis of age across the years. Mann-Whitney $U$ test was used for the study of gender and residence. The confidence level was set at $P<0.05$ unless specified.

\section{Results}

\section{Overview of Outpatients}

Records from a total number of 16,605 first-episode patients with clinical diagnosis (3958 in 2017, 4517 in 2018, 4792 in 2019, and 3338 in 2020) and 134,160 follow-up
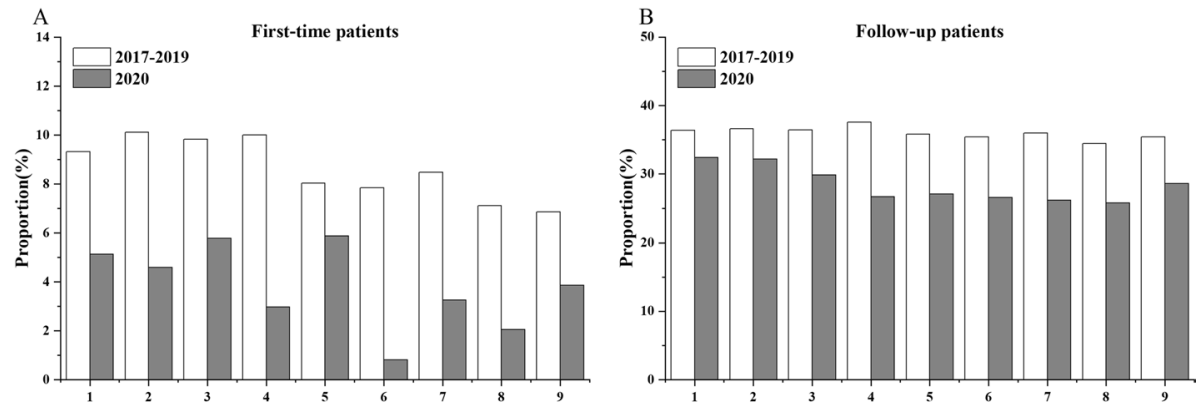

Fig. 2 Relative change of incidence of schizophrenia. First-time patients (A) and follow-up patients (B) near the Spring festival of 2017-2019 and 2020. Incidence is the proportion of schizophrenia in the total number of first-episode outpatients. The relative change was calculated as the ratio to the first data point (in percentage). The data is analyzed every 10 days as a statistical point (the last statistical point is 11 days) 
patients $(26,757$ in $2017,35,877$ in $2018,38,240$ in $2019,33,286$ in 2020) were enrolled for detailed analysis. We first compared the year-by-year change in the number of outpatients in a similar period from 2017 to 2020 (Fig. 1A). The number of outpatients significantly decreased in 2020 ( $-14.89 \%$, compared with 2019) and ended the upward trend since 2017. A month-by-month comparison further showed that the decrease of outpatients was mainly in February (-32.98\%, Fig. 1B), when the COVID-19 outbreak was peaked in China. Unless otherwise stated, all the following analyses are based on the ratio of schizophrenia to the total number of outpatients to minimize the impact of the absolute number of outpatients.

\section{Overall Incidence of First-Episode Schizophrenia Dropped in 2020}

To examine if the observation of an increased number of aged adults of first-episode schizophrenia was a result of changing prevalence of schizophrenia, we first reviewed the incidence of first-episode schizophrenia by calculating the ratio of schizophrenia (F20) both in first-time and follow-up patients (Fig. 2). For first-time patients, the incidence of schizophrenia from January to March in 2020 was continuously lower than that from 2017 to 2019 with a high level of variation (Fig. 2A). For follow-up patients, the incidence of schizophrenia was also lower in 2020, but the frequency was much more stable compared with first-time patients (Fig. 2B).

\section{AFD of Patients Largely Increased in January and February 2020}

We then further analyzed clinical records to find out if the demographics of first-episode schizophrenia have changed since January 2020. Table 2 shows the statistics of age,

Table 2 Comparison of population information of schizophrenia

\begin{tabular}{|c|c|c|c|c|c|c|}
\hline & \multicolumn{2}{|c|}{ First-time patients, $n \pm s / n(\%)$} & \multirow[t]{2}{*}{$t / Z$} & \multicolumn{2}{|c|}{ Follow-up patients, $n \pm s / n(\%)$} & \multirow[t]{2}{*}{$t / Z$} \\
\hline & 2017-2019 & 2020 & & 2017-2019 & 2020 & \\
\hline Age & $40.79 \pm 15.40$ & $44.85 \pm 15.31$ & $-2.440^{*}$ & $40.17 \pm 13.71$ & $40.44 \pm 13.34$ & -1.647 \\
\hline Jan & $40.77 \pm 15.26$ & $46.60 \pm 15.14$ & $-2.365^{*}$ & $39.92 \pm 13.77$ & $40.16 \pm 13.30$ & -0.926 \\
\hline Feb & $39.69 \pm 15.10$ & $51.53 \pm 14.74$ & $-2.959^{* *}$ & $40.08 \pm 13.59$ & $40.70 \pm 13.31$ & -1.917 \\
\hline Mar & $42.04 \pm 15.83$ & $39.89 \pm 14.59$ & 0.768 & $40.50 \pm 13.77$ & $40.58 \pm 13.41$ & -0.265 \\
\hline Gender & & & -1.018 & & & $-2.055^{*}$ \\
\hline Male & $330(43.5)$ & $47(49.0)$ & & $14,835(48.6)$ & $4066(47.3)$ & \\
\hline Female & $429(56.5)$ & $49(51.0)$ & & $15,704(51.4)$ & $4526(52.7)$ & \\
\hline Region & & & $-9.337^{* *}$ & & & $-83.242^{* *}$ \\
\hline Urban & $116(15.3)$ & $36(37.5)$ & & $6358(20.8)$ & $4180(48.6)$ & \\
\hline Suburb & $135(17.8)$ & 45 (46.9) & & $5394(17.7)$ & $3822(44.5)$ & \\
\hline Other & $508(66.9)$ & $15(15.6)$ & & 18,787 (61.5) & $590(6.9)$ & \\
\hline
\end{tabular}

Independent age $t$ test was used for age comparison, and Mann-Whitney $U$ test was used for analysis of gender and residence

${ }^{*} P<0.05$

${ }^{* *} P<0.01$ 
Fig. 3 Age distribution of patients with schizophrenia. Left panels are the age distribution of patients with schizophrenia for the first time in January (A), February (C), and March (E). Right panels are the age distribution of follow-up patients with schizophrenia in January (B), February (D), and March (F). Gray bar, data in 2020; White bar, data collected from 2017-2019

gender, and approximate addresses of both first-time and follow-up patients. For first time patients, the averaged AFD significantly increased in January and February but returned to normal level in March compared with similar periods from 2017-2019. In January 2020, AFD increased from 40.77 $\pm 15.26(2017-2019, n=759)$ to $46.60 \pm 15.14$ $(2020, n=96)(t=-2.365, P=0.019$, independent sample $t$ test $)$. The difference was further enlarged in February 2020 (39.69 $\pm 15.10,2017-2019,51.53 \pm 14.74,2020$, $t=-2.959, P=0.003$ ). This statistical difference disappeared in March 2020. Besides, no significant changes in age were found in follow-up patients. For first-episode schizophrenia, the gender difference was not significant $(Z=-1.018, P=0.309)$. For follow-up patients diagnosed with schizophrenia, the gender difference was significant in $(Z=-2.055, P=0.040)$.

We then plotted the distribution of AFD (Fig. 3) to understand the underlying change in first-time patients better. Figure 3 shows the histogram of AFD from January to March for both the first time. Different from the unimodal distribution peaked near 18-34 years old in 2017-2019, which is matched with previous reports (Häfner et al., 1998), a unimodal distribution centered at 50-64 years old can be found from clinical records in January and February in 2020. Interestingly, although there is no significant change between AFD in March, the bimodal distribution of AFD shown in Fig. 3E suggests the incidence of schizophrenia in aged adults was still high.

\section{Discussion}

This study discovered a significant drop in psychiatric outpatient visits in 2020, which was primarily centered in February. The sharp decline of outpatients in February could be a result of anti-epidemic measures such as countrywide restrictions of public transportation. Furthermore, we discovered that the incidence of schizophrenia in first-time patients with a primary diagnosis was consistently lower and more variable in JanuaryMarch 2020 than in 2017-2019. In 2020, however, the incidence of schizophrenia in follow-up patients was significantly more stable in frequency than in primary patients, although being lower. These results suggested that the incidence of first-episode schizophrenia dropped in 2020 and should not be the cause of observed abnormality in patient age.

Previous research has shown that significant crises and disasters can cause people to experience negative emotions such as anxiety, depression, and anger in the short term (Kane et al., 2018). Long-term effects include suffering from posttraumatic stress disorder, depression, phobia, obsessive-compulsive disorder, and substance abuse (Inoue et al., 2019; Reifels et al., 2019). Similarly, researchers discovered a rise in negative feelings in the population during the COVID-19 epidemic, including anxiety, fear, psychological distress, and depression (Bauerle et al., 2020; Luo et al., 2020). Although the effects are widespread, these mental disorders have a relatively limited impact on patients' social functioning. This retrospective study found an abnormal increase in aged adults in first-episode schizophrenia during the COVID-19 outbreak. It may be a dangerous signal because 

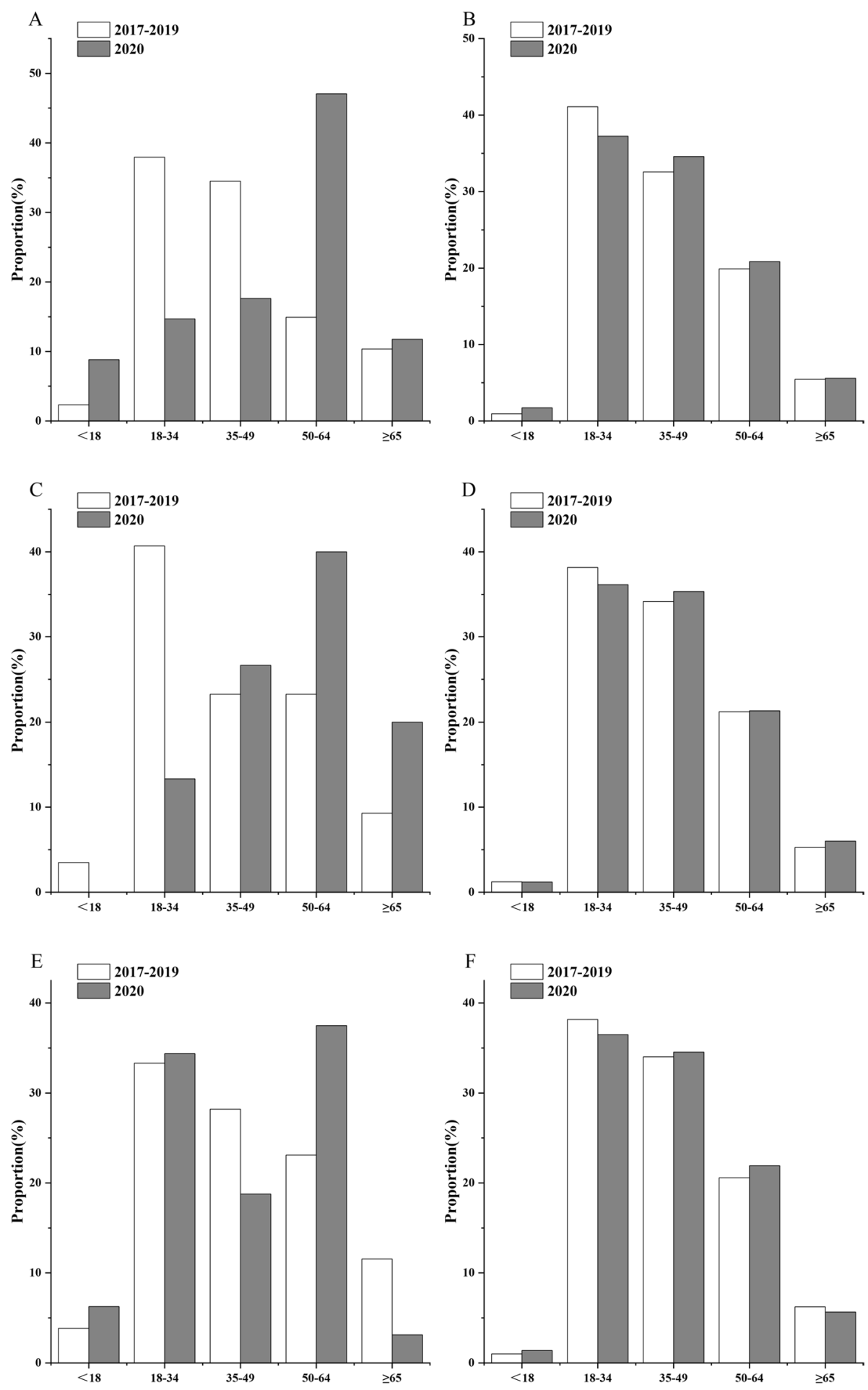
schizophrenia is considered as severe mental disorders, which can seriously affect the social functioning of patients. Although the pathogenesis of schizophrenia is still unknown, stressful events or environments may lead to deterioration of psychiatric symptoms, which may be related to weak susceptibility to stress in the early stages of schizophrenia (Horan et al., 2005).

It has been found that a severe epidemic like SARS in 2003 could result in a sharp rise in suicide rates, especially among the elders (Chan et al., 2006; Cheung et al., 2008). During the COVID-19 pandemic, some researchers have raised concerns about the possibility of suicide among the elderly (de Leo \& Trabucchi, 2020; Sher, 2020; Wand et al., 2020). Possible reasons include the collapse of social networks and the difficulty of obtaining medical services. As mentioned earlier, COVID-19 is also known to be more lethal to elders, especially those who are over 65 (Guan et al., 2020). These findings all suggested that aged people could be mentally sensitive to the outbreak of COVID-19. One issue that is different from the previous situation, like SARS in 2003, is that the whole world has become an information society in the past 20 years. Even if you live in a city where only a few or no infections were found, the rapid spreading of COVID-19 could still mentally affect you through various kinds of social media. Uncountable news and information are generated on the Internet every day, and almost everyone has a smartphone to obtain the latest updates of COVID-19 through social media (e.g., Twitter, Facebook, and TikTok). While timely and transparent information is critically helpful for stopping severe infectious diseases like COVID-19, too much information might also bring a heavy burden to the nerve of each person, especially after weeks of traffic control. It could also increase the risk of severe mental disorders such as schizophrenia. One known feature of COVID-19 is that it is much more lethal to elders, especially those who have underlying diseases (Epidemiology Working Group for NCIP Epidemic Response, Chinese Center for Disease Control and Prevention, 2020; Guan et al., 2020). The mortality rate of COVID-19 gradually increases in patients over 50 years of age, and $27 \%$ of patients who are over 65 are severed cases (Guan et al., 2020). The results of our retrospective study showed that the age of onset of patients with first-episode schizophrenia during the COVID-19 outbreak was significantly older.

Gender has been known as a risk factor in multiple mental disorders (Keane et al., 2006; Riecher-Rossler et al., 2018). In this study, no significant differences were found in the sex of schizophrenic patients during the epidemic. It was suggested that gender is not a risk factor here, and it is also consistent with case reports of COVID-19 in which no gender difference was found (Guan et al., 2020). According to official reports from China CDC, by the end of January 2020, the majority of COVID-19 infections are found in urban regions, especially big cities such as Wuhan. Much fewer cases were found in suburban areas where population density is low. But in this study, there is no significant difference in the impact of being in a city on schizophrenia.

In summary, we believe that during the COVID-19 outbreak, the elderly have an increased risk of developing schizophrenia. Although strict quarantine measures have affected the outpatient visits of the floating population, we do not think it is because the decrease in the number of young people visiting has led to changes in the age of newly diagnosed schizophrenic patients. On the one hand, the clinical characteristics of young people who have schizophrenia are more severe negative symptoms and cognitive dysfunction, so the social function is severely impaired (Bellino et al., 2004). On the other hand, as an essential labor force, young people are the primary source of income for a family and the family's dependence and hope. Therefore, when they have schizophrenia, they can often be diagnosed and treated in time. In contrast, elderly patients with schizophrenia may 
have difficulties in accessing medical services and fewer outpatient visits (Barry et al., 2002). Therefore, we should pay attention to the impact of COVID-19 on the mental health of the elderly in addition to their physical health, and its impact mechanism needs further study. Because of the significant change of AFD of schizophrenia, which in January and February was only found in first-episode outpatients but not follow-up patients, these findings may be important for the general healthy public. We thus call on psychiatrists and researchers in different regions to join together to share data and work together to counter potential challenges to public mental health caused by the pandemic.

Please be noted that, there are still some limitations in this retrospective study. First, this study originated from anomalies detected by clinicians during diagnosis and therefore did not thoroughly examine all the underlying factors of schizophrenic episodes. Second, the clinical data of outpatients was collected from only one regional psychiatric center. Thus, the conclusion could be biased to specific region. Third, because the countrywide pandemic in China lasted only about 3 months, the long-term effects of the COVID-19 pandemic on schizophrenia episodes is still unclear. This needs to be answered by studies from other researches.

Abbreviations SARS: Severe acute respiratory syndrome; MERS: Middle East respiratory syndrome; AFD: The age of first diagnosis; ICD-10: The International Classification of Diseases 10th Edition

Acknowledgements We sincerely appreciate all the people, especially doctors and nurses who are heroically battling this disease now.

Funding This study was funded by the National Natural Science Foundation of China (31771152, 31970932) and Youth Medical Science and Technology Innovation Project of Xuzhou Health Commission (XWKYHT20200015). Neither the funder nor the sponsor of the study had any role in the study design, the collection, analysis or interpretation of data, or the writing of the report.

Data Availability The datasets used and/or analyzed during the current study are available from the corresponding author on reasonable request. An early preprint version of this manuscript can be found at http:// www.chinaxiv.org/abs/202003.00003.

\section{Declarations}

Ethics Approval and Consent to Participate This retrospective study has been reviewed and approved by the ethical board at The Affiliated Xuzhou Eastern Hospital of Xuzhou Medical University. We were granted limited access to client files. All respondents were exempted from signing an informed consent form.

Consent for Publication Not applicable.

Competing Interests The authors declare no competing interests.

\section{References}

Aviv, A., Bromberg, G., Baruch, Y., Shapira, Y., \& Blass, D. M. (2011). The role of environmental influences on schizophrenia admissions in Israel. International Journal of Social Psychiatry, 57(1), 57-68. https://doi.org/10.1177/0020764009348444

Bailly, D. (2009). Adolescence and schizophrenia. Encephale, 35(Suppl 1), S10-19. https://doi.org/10.1016/ s0013-7006(09)75527-7

Barry, K. L., Blow, F. C., Dornfeld, M., \& Valenstein, M. (2002). Aging and schizophrenia: Current health services research and recommendations. Journal of Geriatric Psychiatry and Neurology, 15(3), 121127. https://doi.org/10.1177/089198870201500302 
Bauerle, A., Teufel, M., Musche, V., Weismuller, B., Kohler, H., Hetkamp, M., \& Skoda, E. M. (2020). Increased generalized anxiety, depression and distress during the COVID-19 pandemic: A cross-sectional study in Germany. Journal of Public Health (oxford, England), 42(4), 672-678. https://doi.org/ 10.1093/pubmed/fdaa106

Beauchamp, G. A., Ho, M. L., \& Yin, S. (2014). Variation in suicide occurrence by day and during major American holidays. The Journal of Emergency Medicine, 46(6), 776-781.

Bellino, S., Rocca, P., Patria, L., Marchiaro, L., Rasetti, R., Di Lorenzo, R., \& Bogetto, F. (2004). Relationships of age at onset with clinical features and cognitive functions in a sample of schizophrenia patients. Journal of Clinical Psychiatry, 65(7), 908-914. https://doi.org/10.4088/jcp.v65n0705

Belvederi Murri, M., Zotos, S., Cantarelli, L., Berardi, L., Curtarello, E. M. A., Folesani, F., \& Grassi, L. (2021). Between China and Italy: A case report of first-episode schizophrenia in the Covid-19 era. Psychiatry Research, 298, 113804. https://doi.org/10.1016/j.psychres.2021.113804

Chan, S. M., Chiu, F. K., Lam, C. W., Leung, P. Y., \& Conwell, Y. (2006). Elderly suicide and the 2003 SARS epidemic in Hong Kong. International Journal of Geriatric Psychiatry, 21(2), 113-118. https:// doi.org/10.1002/gps.1432

Charlson, F. J., Ferrari, A. J., Santomauro, D. F., Diminic, S., Stockings, E., Scott, J. G., \& Whiteford, H. A. (2018). Global epidemiology and burden of schizophrenia: Findings from the global burden of disease study 2016. Schizophrenia Bulletin, 44(6), 1195-1203. https://doi.org/10.1093/schbul/sby058

Chen, R., Chou, K. R., Huang, Y. J., Wang, T. S., Liu, S. Y., \& Ho, L. Y. (2006). Effects of a SARS prevention programme in Taiwan on nursing staff's anxiety, depression and sleep quality: A longitudinal survey. International Journal of Nursing Studies, 43(2), 215-225. https://doi.org/10.1016/j.ijnurstu.2005. 03.006

Cheung, Y. T., Chau, P. H., \& Yip, P. S. (2008). A revisit on older adults suicides and severe acute respiratory syndrome (SARS) epidemic in Hong Kong. International Journal of Geriatric Psychiatry, 23(12), 1231-1238. https://doi.org/10.1002/gps.2056

Choi, E. P. H., Hui, B. P. H., \& Wan, E. Y. F. (2020). Depression and anxiety in Hong Kong during COVID19. International Journal of Environmental Research and Public Health, 17(10). https://doi.org/10. 3390/ijerph17103740

de Leo, D., \& Trabucchi, M. (2020). COVID-19 and the fears of Italian senior citizens. International Journal of Environmental Research and Public Health, 17(10). https://doi.org/10.3390/ijerph17103572

Epidemiology Working Group for NCIP Epidemic Response Chinese Center for Disease Control and Prevention. (2020). The epidemiological characteristics of an outbreak of 2019 novel coronavirus diseases (COVID-19) in China. Zhonghua Liu Xing Bing Xue Za Zhi, 41(2), 145-151. https://doi.org/10.3760/ cma.j.issn.0254-6450.2020.02.003

Guan, W. J., Ni, Z. Y., Hu, Y., Liang, W. H., Ou, C. Q., He, J. X., \& Zhong, N. S. (2020). Clinical characteristics of coronavirus disease 2019 in China. New England Journal of Medicine, 382(18), 1708-1720. https://doi.org/10.1056/NEJMoa2002032

Häfner, H., an der Heiden, W., Behrens, S., Gattaz, W. F., Hambrecht, M., Löffler, W., . . Stein, A. (1998). Causes and consequences of the gender difference in age at onset of schizophrenia. Schizophr Bull, 24(1), 99-113. https://doi.org/10.1093/oxfordjournals.schbul.a033317

He, P., Luo, Y., Guo, C., Chen, G., Song, X., \& Zheng, X. (2019). Prenatal war exposure and schizophrenia in adulthood: Evidence from the Sino-Japanese War of 1937-1945. Social Psychiatry and Psychiatric Epidemiology, 54(3), 313-320. https://doi.org/10.1007/s00127-018-1584-0

Horan, W. P., Ventura, J., Nuechterlein, K. H., Subotnik, K. L., Hwang, S. S., \& Mintz, J. (2005). Stressful life events in recent-onset schizophrenia: Reduced frequencies and altered subjective appraisals. Schizophrenia Research, 75(2-3), 363-374. https://doi.org/10.1016/j.schres.2004.07.019

Inoue, Y., Stickley, A., Yazawa, A., Aida, J., Kawachi, I., Kondo, K., \& Fujiwara, T. (2019). Adverse childhood experiences, exposure to a natural disaster and posttraumatic stress disorder among survivors of the 2011 Great East Japan earthquake and tsunami. Epidemiology and Psychiatric Sciences, 28(1), 45-53. https://doi.org/10.1017/S2045796017000233

Jagadheesan, K., Danivas, V., Itrat, Q., Shekaran, L., \& Lakra, V. (2021). A 6-month study on the pattern of emergency department presentations for schizophrenia and other psychotic disorders during COVID19 lockdown. Psychiatry Research, 303, 114081. https://doi.org/10.1016/j.psychres.2021.114081

Kane, J. C., Luitel, N. P., Jordans, M. J. D., Kohrt, B. A., Weissbecker, I., \& Tol, W. A. (2018). Mental health and psychosocial problems in the aftermath of the Nepal earthquakes: Findings from a representative cluster sample survey. Epidemiology and Psychiatric Sciences, 27(3), 301-310. https://doi. org/10.1017/S2045796016001104 
Keane, T. M., Marshall, A. D., \& Taft, C. T. (2006). Posttraumatic stress disorder: Etiology, epidemiology, and treatment outcome. Annual Review of Clinical Psychology, 2, 161-197. https://doi.org/10.1146/ annurev.clinpsy.2.022305.095305

Loranger, A. W. (1984). Sex difference in age at onset of schizophrenia. Archives of General Psychiatry, 41(2), 157-161. https://doi.org/10.1001/archpsyc.1984.01790130053007

Luo, M., Guo, L., Yu, M., Jiang, W., \& Wang, H. (2020). The psychological and mental impact of coronavirus disease 2019 (COVID-19) on medical staff and general public - A systematic review and metaanalysis. Psychiatry Research, 291, 113190. https://doi.org/10.1016/j.psychres.2020.113190

McCutcheon, R. A., Reis Marques, T., \& Howes, O. D. (2020). Schizophrenia-An overview. JAMA Psychiatry, 77(2), 201-210. https://doi.org/10.1001/jamapsychiatry.2019.3360

McGrath, J. J., Pemberton, M. R., Welham, J. L., \& Murray, R. M. (1994). Schizophrenia and the influenza epidemics of 1954, 1957 and 1959: A southern hemisphere study. Schizophrenia Research, 14(1), 1-8. https://doi.org/10.1016/0920-9964(94)90002-7

Neill, E., Tan, E. J., Toh, W. L., Selvendra, A., Morgan, V. A., Rossell, S. L., \& Castle, D. J. (2020). Examining which factors influence age of onset in males and females with schizophrenia. Schizophrenia Research, 223, 265-270. https://doi.org/10.1016/j.schres.2020.08.011

Oloniniyi, I. O., Ibigbami, O. I., Amiola, A., Esan, O. A., \& Esan, O. O. (2021). First episode psychosis during COVID-19 pandemic: A case series. West African Journal of Medicine, 38(6), 599-603. Retrieved August 29, 2021, from https://www.ncbi.nlm.nih.gov/pubmed/34180216

Parma, V., Ohla, K., Veldhuizen, M. G., Niv, M. Y., Kelly, C. E., Bakke, A. J., \& Hayes, J. E. (2020). More than smell-COVID-19 is associated with severe impairment of smell, taste, and chemesthesis. Chemical Senses, 45(7), 609-622. https://doi.org/10.1093/chemse/bjaa041

Reifels, L., Mills, K., Duckers, M. L. A., \& O'Donnell, M. L. (2019). Psychiatric epidemiology and disaster exposure in Australia. Epidemiology and Psychiatric Sciences, 28(3), 310-320. https://doi.org/10. 1017/S2045796017000531

Riecher-Rossler, A., Butler, S., \& Kulkarni, J. (2018). Sex and gender differences in schizophrenic psychoses-A critical review. Archives of Women's Mental Health, 21(6), 627-648. https://doi.org/10.1007/ s00737-018-0847-9

Sansone, R. A., \& Sansone, L. A. (2011). The christmas effect on psychopathology. Innovations in Clinical Neuroscience, 8(12), 10-13. Retrieved March 15, 2021, from https://www.ncbi.nlm.nih.gov/pubmed/ 22247812

Sher, L. (2020). The impact of the COVID-19 pandemic on suicide rates. QJM, 113(10), 707-712. https:// doi.org/10.1093/qjmed/hcaa202

Suen, Y. N., Wong, S. M. Y., Hui, C. L. M., Chan, S. K. W., Lee, E. H. M., Chang, W. C., \& Chen, E. Y. H. (2019). Late-onset psychosis and very-late-onset-schizophrenia-like-psychosis: An updated systematic review. International Review of Psychiatry, 31(5-6), 523-542. https://doi.org/10.1080/09540261.2019. 1670624

Taha, S., Matheson, K., Cronin, T., \& Anisman, H. (2014). Intolerance of uncertainty, appraisals, coping, and anxiety: The case of the $2009 \mathrm{H} 1 \mathrm{~N} 1$ pandemic. The British Journal of Health Psychology, 19(3), 592-605. https://doi.org/10.1111/bjhp.12058

Valdes-Florido, M. J., Lopez-Diaz, A., Palermo-Zeballos, F. J., Garrido-Torres, N., Alvarez-Gil, P., Martinez-Molina, I., \& Ruiz-Veguilla, M. (2021). Clinical characterization of brief psychotic disorders triggered by the COVID-19 pandemic: A multicenter observational study. European Archives of Psychiatry and Clinical Neuroscience. https://doi.org/10.1007/s00406-021-01256-w

Wand, A. P. F., Zhong, B. L., Chiu, H. F. K., Draper, B., \& De Leo, D. (2020). COVID-19: The implications for suicide in older adults. International Psychogeriatrics, 32(10), 1225-1230. https://doi.org/10.1017/ S1041610220000770

Publisher's Note Springer Nature remains neutral with regard to jurisdictional claims in published maps and institutional affiliations. 